\title{
Comparison of the Decontamination Performance of Three Permeable Bricks: Adsorption and Filtration Experiments
}

\author{
Zizeng Lin*, Hai Yang, Huiming Chen, Xinyu Ouyang, Zhaoqin Liu \\ ${ }^{1}$ College of Civil Engineering, Nanjing Forestry University, Nanjing, PR China
}

Received: 8 October 2019

Accepted: 15 November 2019

\begin{abstract}
To investigate the removal mechanism of pollutants from urban rainfall runoff by permeable brick, ceramic brick, cement brick and steel slag brick were applied to study their decontamination performance. An adsorption experiment with granular materials obtained by crushing the bricks and a filtration experiment with complete bricks were carried out, and suspended solids (SS), chemical oxygen demand (COD), total organic carbon (TOC), dissolved organic carbon (DOC), ammonia nitrogen $\left(\mathrm{NH}_{4}^{+}-\mathrm{N}\right)$, total nitrogen $(\mathrm{TN})$, total phosphorus (TP) and heavy metals $(\mathrm{Cu}, \mathrm{Zn}$ and $\mathrm{Pb})$ in the influent and effluent were measured. The results showed that (I) $\mathrm{NH}_{4}^{+}-\mathrm{N}, \mathrm{TN}$ and $\mathrm{COD}$ dissolved out from most of the particulate materials during the adsorption process. (II) The filtration performance of permeable bricks for dissolved pollutants such as $\mathrm{COD}, \mathrm{NH}_{4}{ }^{+}-\mathrm{N}$ and TN was inferior to that for SS, TP and heavy metals. The soluble substances were difficult to intercept, and the release from the brick materials was the reason for the low removal rate. (III) The compact and dense pore distribution was conducive to the removal of organic carbon particles larger than $0.45 \mu \mathrm{m}$, and non-sintered bricks had higher DOC removal than the other bricks because of the flocculation of cement hydration products. The study could offer a new perspective for the decontamination of permeable bricks.
\end{abstract}

Keywords: permeable brick, adsorption, filtration, decontamination

\section{Introduction}

In recent years, permeable pavements have become one of the most frequently used low-impact development (LID) techniques $[1,2]$. This infiltration-based technology consists of structural layers with relatively high porosity to allow rainwater to pass through its surface and underlying layers, including a permeable pavement surface, aggregate subbases, and sometimes

*e-mail: linzizeng@njfu.edu.cn including geotextiles and underdrains, eventually infiltrating into the natural soil or discharging into a drainage system [3, 4].

In addition to a good hydrological effect in reducing runoff, delaying peak flow, increasing infiltration rate and recharging the groundwater $[5,8]$, a permeable brick paving system (PPS) also exhibits good decontamination potential in improving water quality [9-15]. Many scholars have researched the management performance of PPSs. Fassman et al. found that the runoff reduction rate and flood peak reduction rate of a PPS were $72 \%$ and $89 \%$, respectively, in power 
clay conditions [5], while Collins et al. found that the runoff reduction rate and flood peak reduction rate of a PPS were $38-66 \%$ and $60-77 \%$, respectively, in clay conditions [6]. More studies on runoff rainwater quality for permeable pavement have shown that PPSs are highly effective in the mitigation of pollutants in rainwater runoff, not only for removing suspended solids but also for decreasing total phosphorus and heavy metals [9-15]. For example, research has shown that suspended solids, total phosphorus and lead can be decreased by up to $64 \%, 74.2 \%$ and $79 \%$, respectively [11].

However, few studies have focused on the surface layer of a PPS, namely the surface permeable brick. In fact, the effect of the permeable brick on water purification is very significant. As the surface layer of the PPS, the permeable brick is the first layer that contacts directly with the runoff. The characteristics of the brick noticeably affect the runoff quality [16, 17]. Li et al. found that shale brick had a substantial removal effect on nearly all kinds of pollutants in runoff, but for five other surface bricks it was merely several pollutants [16]. Furthermore, the composition of the material in the brick itself also directly affects the quality of the rainwater. Some permeable bricks containing cement are alkaline in nature, and they release hydroxide ions and carbonate ions when in contact with rainwater, which increases the $\mathrm{pH}$ of the effluent $[3,17]$. Research has shown that the $\mathrm{pH}$ values rapidly increased at first, followed by a gradual decrease and an eventual stabilization at approximately 10.77 compared with a $\mathrm{pH}$ of 7.40 of raw water for cement brick [17].

The removal mechanism of pollutants in runoff by surface-permeable bricks mainly includes physical interception and adsorption [2, 13-15]. Studies have shown that surface-permeable bricks have different removal efficiencies for different pollutants. For example, ceramic permeable brick could effectively remove $79.8 \%$ of suspended solids (SS) and $74.2 \%$ of TP in runoff, while it had little effect on the COD, $\mathrm{NH} 4+-\mathrm{N}$ and $\mathrm{TN}$, with removal rates of $24.1 \%, 3.25 \%$ and $3.25 \%$, respectively [18]. The removal efficiencies vary widely, and it is clear that the removal mechanism is also very different; more attention should be focused on the removal mechanism and influence. In the removal effect of permeable brick on actual road rainwater, DOC is a very active organic component that can be used as the transport carrier or ligand of many organic and inorganic pollutants, affecting the toxicity of other pollutants in the environment $[19,20]$. Therefore, the actual filtering effect of DOC needs to be further investigated.

In this study, ceramic brick, concrete brick and steel slag brick were chosen for experimental research to fully investigate the removal mechanism of different pollutants by common permeable bricks. The adsorption experiment of particle materials obtained by crushing brick and the filtration experiment of complete brick were carried out, and then actual road rainwater was filtered to investigate the effectiveness of removing organic carbon. The concentrations of SS, COD, $\mathrm{NH}_{4}^{+}-\mathrm{N}, \mathrm{NO}_{3}^{-}-\mathrm{N}, \mathrm{TN}, \mathrm{TP}$ and heavy metals $(\mathrm{Cu}, \mathrm{Zn}$ and $\mathrm{Pb}$ ) were measured, and the main removal mechanism of pollutants was further discussed. The objectives and novelties of this research were to explore the pollutant removal mechanism of permeable bricks through adsorption and filtration experiments, which could offer a new perspective for research on the decontamination of permeable bricks.

\section{Materials and Methods}

\section{Permeable Brick and Particle Materials}

The three permeable bricks measuring $20 \times 20 \times$ $5.5 \mathrm{~cm}$ were purchased from the Nanjing local building materials market. All three bricks can be divided into two layers, and the upper layer has a thickness of approximately $1.0 \mathrm{~cm}$ with a relatively smaller particle diameter, and the lower layer is approximately $4.5 \mathrm{~cm}$ thick. The main properties of the three permeable bricks all meet the requirements of the Chinese national standard, permeable paving bricks and permeable paving flags (GB/T 25993-2010). The specific physical and chemical properties of the three bricks are shown in Tables 1 and 2 .

The particle materials were obtained by crushing the brick using a crusher, and the materials were sieved to achieve the same diameter of 2.0-5.0 $\mathrm{mm}$. The granular materials were soaked for 3 days and washed repeatedly

Table 1. The main physical properties of three permeable bricks.

\begin{tabular}{|c|c|c|c|c|}
\hline Index & GB/T25993-2010 & Ceramic brick & Cement brick & Slag brick \\
\hline \multirow{2}{*}{ Splitting tensile strength (MPa) } & Average value $\geq 4.5$ & 5.3 & 4.8 & 4.8 \\
\cline { 2 - 5 } & Minimum value $\geq 3.4$ & 4.7 & 4.1 & 3.8 \\
\hline Permeability coefficient (cm/s) & $\geq 2.0 \times 10^{-2}$ & $3.1 \times 10^{-2}$ & $3.6 \times 10^{-2}$ & $2.6 \times 10^{-2}$ \\
\hline Frost resistance (\%) & Strength loss rate $\leq 20 \%$ & $4 \%$ & $4.7 \%$ & $2.1 \%$ \\
\hline BPN (British Pendulum Number) & $\geq 65$ & 89 & 76 & 85 \\
\hline Porosity (\%) & $\geq 15$ & $24.82 \%$ & $26.72 \%$ & $24.29 \%$ \\
\hline
\end{tabular}


Table 2. Chemical composition of three permeable bricks.

\begin{tabular}{|c|c|c|c|c|c|c|c|c|c|c|}
\hline Composition & $\mathrm{SiO}_{2}$ & $\mathrm{Al}_{2} \mathrm{O}_{3}$ & $\mathrm{CaO}$ & $\mathrm{K}_{2} \mathrm{O}$ & $\mathrm{Fe}_{2} \mathrm{O}_{3}$ & $\mathrm{MgO}$ & $\mathrm{Na}_{2} \mathrm{O}$ & $\mathrm{FeO}$ & $\mathrm{S}$ & $\mathrm{Else}$ \\
\hline Ceramic brick & 69.32 & 17.50 & 2.58 & 2.23 & 1.42 & 1.32 & 3.98 & 0 & 0 & 1.65 \\
\hline Steel slag brick & 11.34 & 2.28 & 38.65 & 0 & 14.84 & 4.22 & 0 & 22.94 & 0.56 & 5.17 \\
\hline Cement brick & 24.89 & 7.59 & 50.65 & 0.76 & 4.53 & 8.98 & 0.52 & 0 & 0 & 2.08 \\
\hline
\end{tabular}

a)
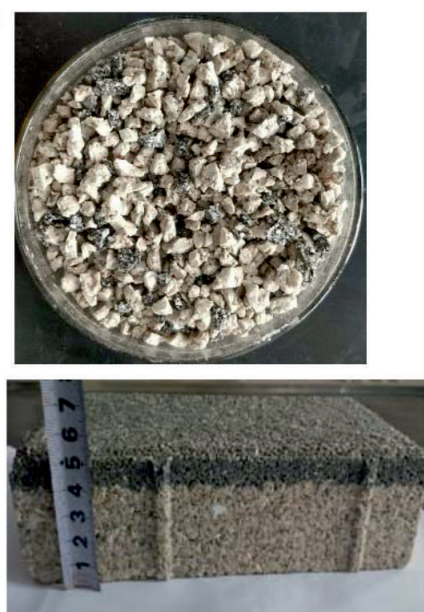

b)

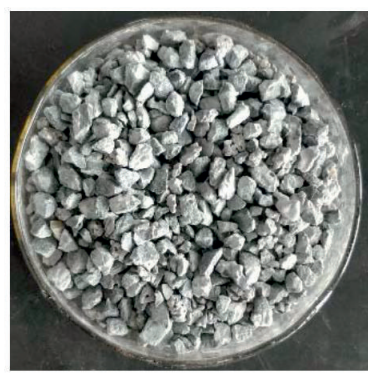

c)
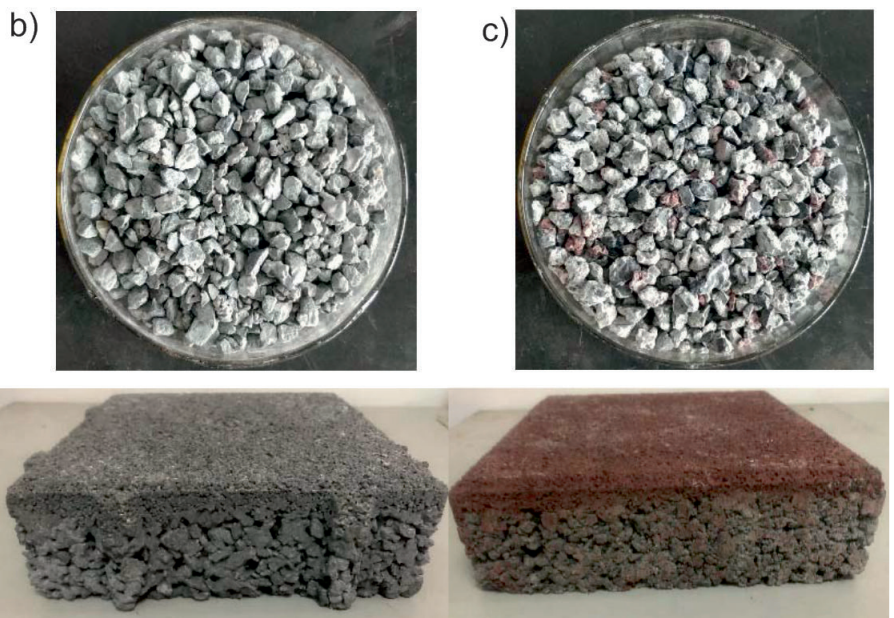

Fig. 1. Three permeable bricks and particle materials.

with distilled water 3 times to remove impurities such as organic matter attached to the surface of the particles. Then the samples were dried in an oven at $105^{\circ} \mathrm{C}$ for 24 $\mathrm{h}$ and stored in grinding jars until use.

\section{Static Adsorption Experiment}

Samples composed of $10 \mathrm{~g}$ of the granular materials with different particle sizes were weighed and transferred into a series of $250 \mathrm{~mL}$ triangular conical flasks, $150 \mathrm{~mL}$ stock solution was added, and the samples were placed in a temperature-regulated orbital platform shaker at $150 \mathrm{r} / \mathrm{min}$. Samples were taken at $1,2,3,4,5,7,12,24,36$ and $60 \mathrm{~h}$ to determine the influence of reaction time on adsorption equilibrium. Then, $50 \mathrm{~mL}$ samples were filtered through $0.45 \mu \mathrm{m}$ hydrophilic membranes prior to analysis, and the filtrate was stored in polyvinyl chloride (PVC) bottles and kept at $4^{\circ} \mathrm{C}$ in the refrigerator.

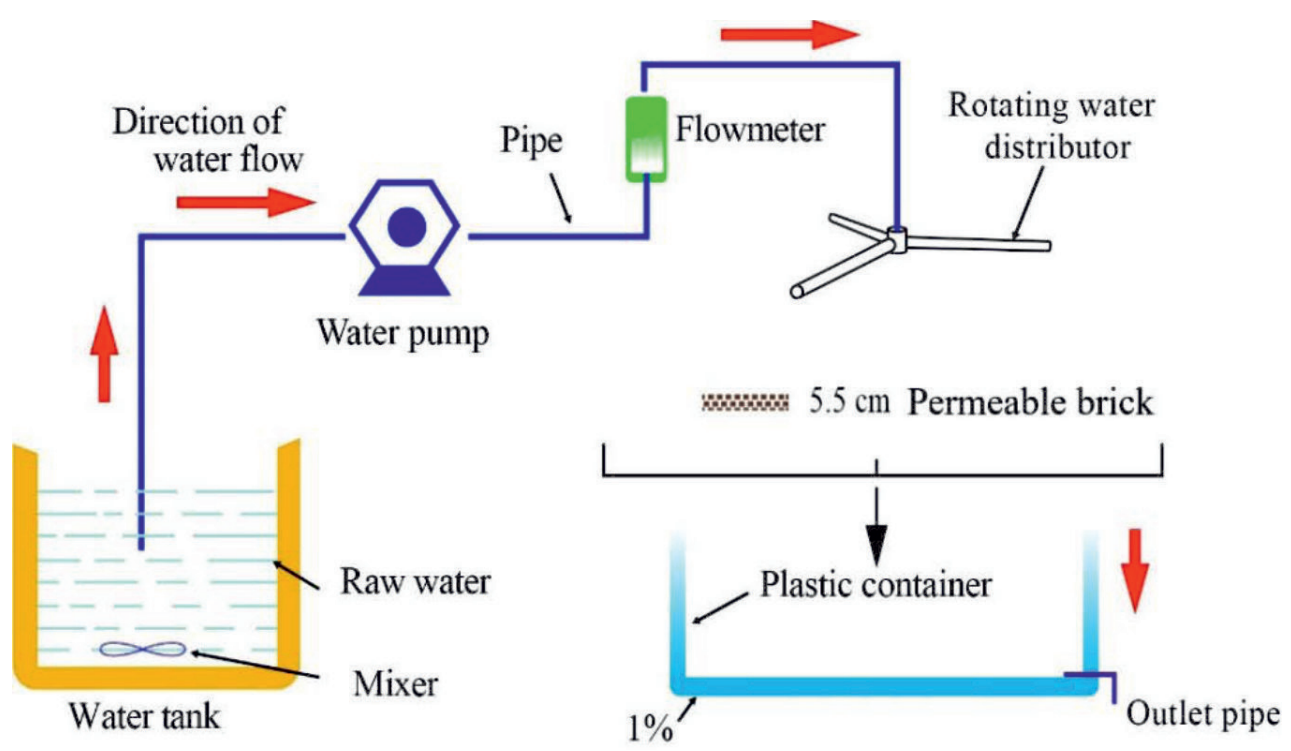

Fig. 2. Schematic of the test device. 


\section{Dynamic Filtration Experiment}

The prepared rainwater was lifted by a water pump and evenly distributed by a rotating water distributor. The pump speed was dynamically adjusted to simulate a 20-year return period, 120-min rainfall in Nanjing. The rainwater was sampled after passing through the ceramic permeable brick and the paving system. Samples were taken every $10 \mathrm{~min}$ for a total of $2 \mathrm{~h}$, while the outlet pipe of the pavement had a stable
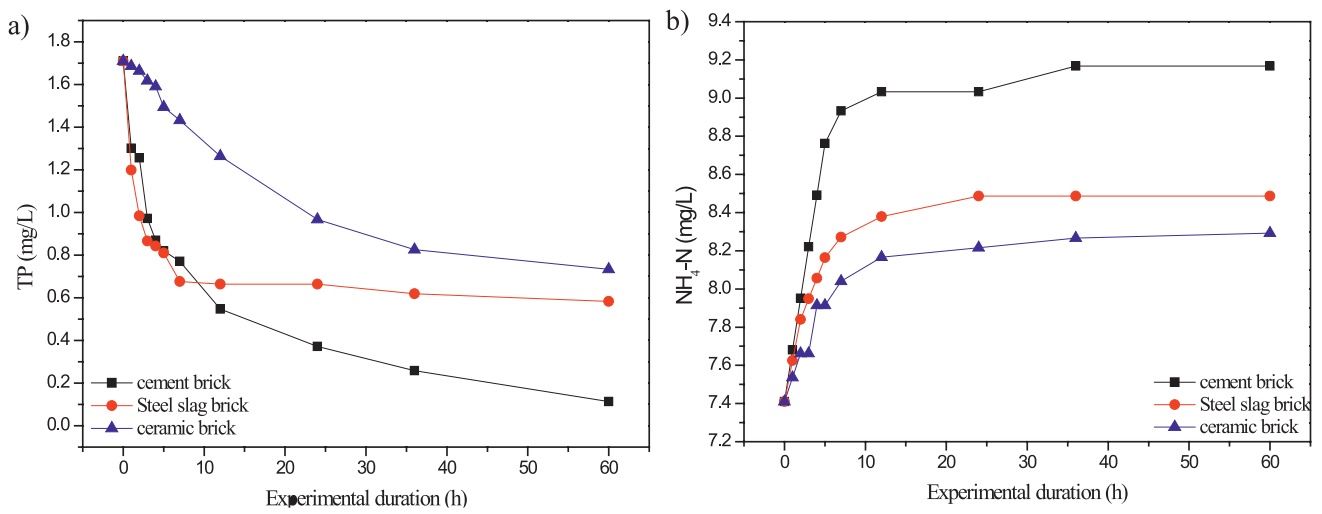

c)
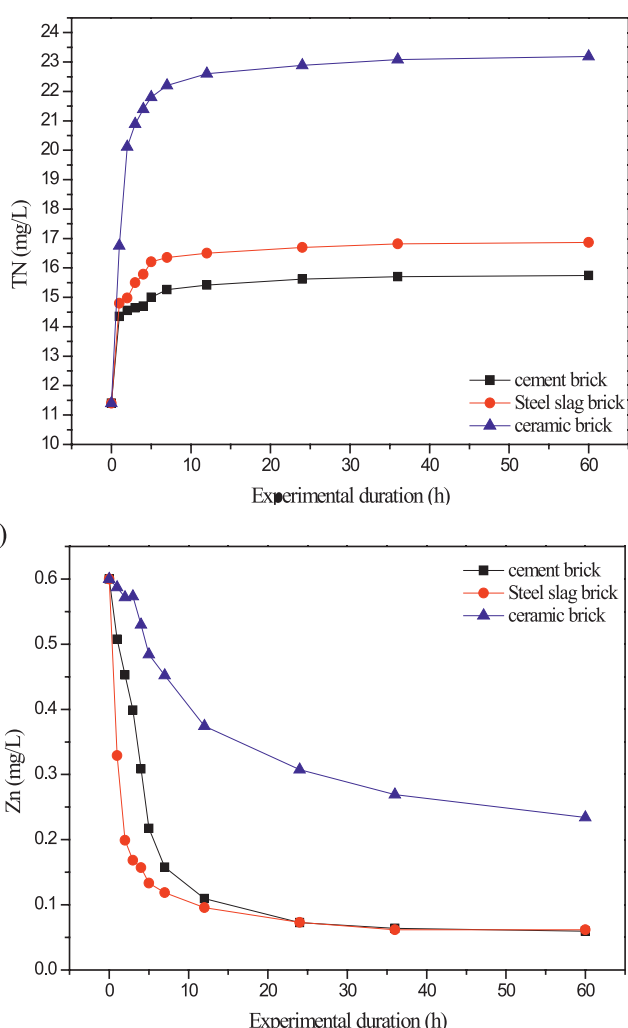

g)

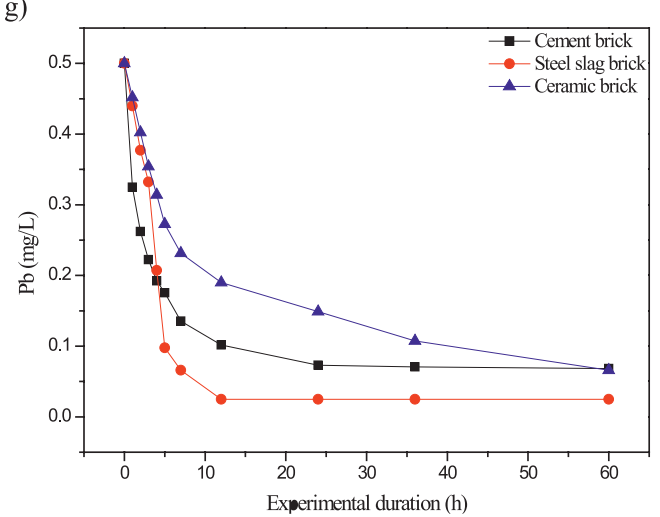

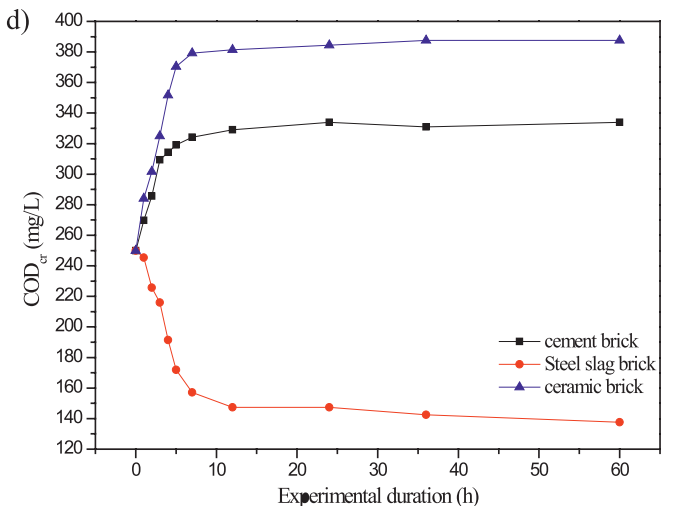

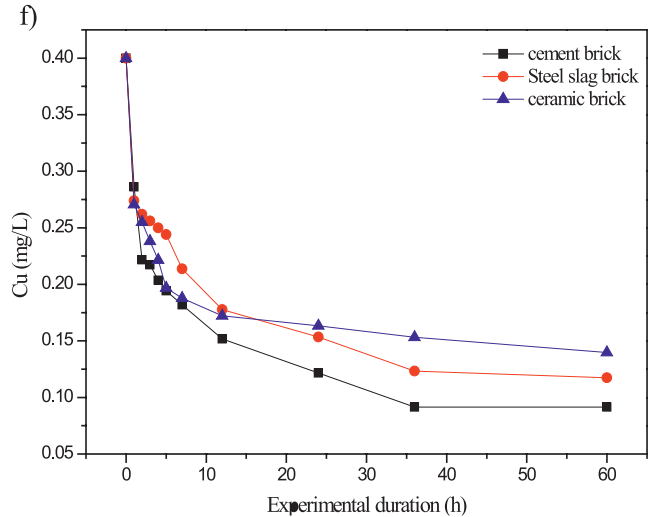

h)

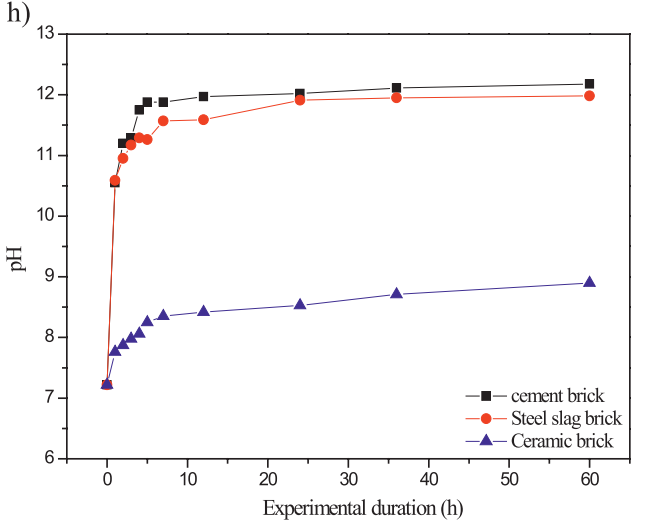

Fig. 3. The adsorption removal of pollutants at different times in three types of bricks. 
outflow. The water sample was collected using a 500-mL polyethylene sampling bottle, and all samples were measured within 48 hours. The test device for the permeable brick paving system is shown in Fig. 2.

\section{Rainfall Concentrations}

Simulated rainfall was carried out according to the situation in Nanjing. The concentrations of various pollutants in the artificially prepared rainwater were $370 \mathrm{mg} / \mathrm{L} \mathrm{SS}, 1.71 \mathrm{mg} / \mathrm{L}$ TP, $11.4 \mathrm{mg} / \mathrm{L} \mathrm{TN}, 250 \mathrm{mg} / \mathrm{L}$ COD, $7.41 \mathrm{mg} / \mathrm{L} \mathrm{NH}_{4}^{+}-\mathrm{N}, 0.4 \mathrm{mg} / \mathrm{L} \mathrm{Cu}, 0.6 \mathrm{mg} / \mathrm{L} \mathrm{Zn}$, and $0.5 \mathrm{mg} / \mathrm{L} \mathrm{Pb}$.

To make the simulated rainwater consistent with actual road rain, the dust next to the roadside was collected, and the turbidity of $800 \mathrm{~g}$ of dust in $20 \mathrm{~L}$ of water was basically the same as that of actual road rainwater. Then, the simulated water was filtered with three kinds of permeable bricks. The values of TOC and DOC before and after filtration were investigated.

\section{Test Methods}

According to the Chinese National Standard Methods (SEPA of China 2002), SS was determined by the gravimetric method (GB 11901-89), COD was determined by the fast digestion-spectrophotometric method (HJ/T 399-2007), the concentrations of $\mathrm{NH}_{3}-\mathrm{N}$, $\mathrm{TN}$, and TP were determined by the spectrophotometric method, and the concentrations of $\mathrm{Zn}, \mathrm{Cu}$ and $\mathrm{Pb}$ were determined by atomic absorption spectrophotometry (TAS-990, China). All the water used in the experiment was ultra-pure water from an ultra-pure water machine (Biosafer-20TAB, China). TOC and DOC were measured by a total organic carbon analyzer (TOC- $\mathrm{V}_{\mathrm{CPN}}$, Japan), and DOC was pretreated with a $0.45 \mu \mathrm{m}$ fiber filter membrane. According to the linear transverse winding test of the standard test method for microscopic determination of parameters of the air-void system in hardened concrete (ASTM C457), the chord size distribution was measured by using an air void analyzer (Rapid air 457, Germany).

\section{Results and Discussion}

\section{Results of the Static Adsorption Experiment}

The adsorption removal of pollutants at different times in the three permeable bricks is shown in Fig. 3, in which the concentrations of $\mathrm{NH}_{4}^{+}-\mathrm{N}, \mathrm{TN}$ and COD increased except for the COD of the steel slag permeable brick, while $\mathrm{TP}$, heavy metals ( $\mathrm{Zn}, \mathrm{Cu}$ and $\mathrm{Pb}$ ) and COD for the steel slag brick decreased with increasing adsorption time, which meant $\mathrm{NH}_{4}^{+}-\mathrm{N}, \mathrm{TN}$ and COD were dissolved out from the particulate materials during the adsorption process. These three kinds of elements were contained in the brick, and these pollutants in the bricks would dissolve into the aqueous solution after breaking and soaking, which may be the reason for the increase in the concentration.

The cement permeable brick has good effectiveness in removing total phosphorus and heavy metals. Grzmil et al. believed that Portland cement could effectively adsorb phosphate in water [21] to form $\left[\mathrm{Ca}_{5}\left(\mathrm{PO}_{4}\right)_{3} \mathrm{~F}\right]$ or $\mathrm{Ca}_{5}\left(\mathrm{PO}_{4}\right)_{3}(\mathrm{OH})_{1-\mathrm{x}} \mathrm{F}_{\mathrm{x}}$ [22]. This may be the reason why the cement brick had the best TP removal rate. The cement permeable bricks had three removal mechanisms for heavy metals. First, the hydration product itself had many pores and a specific surface area to adsorb metal ions. Second, $\mathrm{Ca}, \mathrm{Mg}$ and $\mathrm{Al}$ contained in the cement hydration product undergo

a displacement reaction with the metal cation. Third, a large amount of $\mathrm{OH}^{-}$contained in cement-based materials undergoes a metathesis reaction with heavy metal ions [23-25].

Both the ceramic and cement permeable bricks had organic dissolution phenomena and the steel slag permeable brick did not. Steel slag permeable bricks contain much iron, and iron with a large specific surface area can adsorb dissolved organic matter, which is responsible for the high removal rate of $\operatorname{COD}[26,27]$.

The $\mathrm{pH}$ of the cement and steel slag permeable bricks increased because both of them were nonsintered bricks that contained a certain amount of cement. During the brick forming process, the hydration reaction of the cement produced alkaline substances such as calcium hydroxide, and the contact between the rainwater and alkaline substances or washing out of the alkaline materials led to an increase in the $\mathrm{pH}$ after filtration [3, $16,17]$. Contrary to the non-sintered permeable bricks, the $\mathrm{pH}$ increase in the ceramic permeable brick was not obvious because the high temperature in sintering allowed the raw material to be fully melted without the generation of alkaline materials.

The experimental results showed that the damaged permeable bricks had released some pollutants and might pollute the urban water environment.

\section{Results of the Dynamic Filtration Experiment}

The filtration removal of pollutants at different times in the three permeable bricks is shown in Fig. 4. As shown in Fig. 4, the permeable bricks had good removal effects on SS, TP and heavy metals, and the removal performance of the permeable bricks for dissolved pollutants such as $\mathrm{COD}, \mathrm{NH}_{4}{ }^{+}-\mathrm{N}$ and $\mathrm{TN}$ was inferior to that for SS, TP and heavy metals.

The ceramic permeable brick had the best filtering effect on SS of the three bricks, and research has found that the physical interception of the surface layer inside the permeable brick played a major role in the removal of SS [2, 18], which were mainly filtered by the voids and pores inside the permeable bricks, and the chord size distribution that can be used to characterize the size of the voids and pores was further researched [28]. The chord size was used to represent the size of 
the pores, and the chord length frequency was used to represent the number of pores.

The chord size distribution of the upper layer of the three permeable bricks is shown in Fig. 5. As shown in Fig. 5, the upper layer of the ceramic permeable brick did not contain large particles of 1.5-3.0 mm, and the pore ratio of $0.5-1.5 \mathrm{~mm}$ was smaller than that of the cement and slag bricks, which meant that the ceramic brick had more small pores. This may be the reason why ceramic permeable bricks have a better SS removal
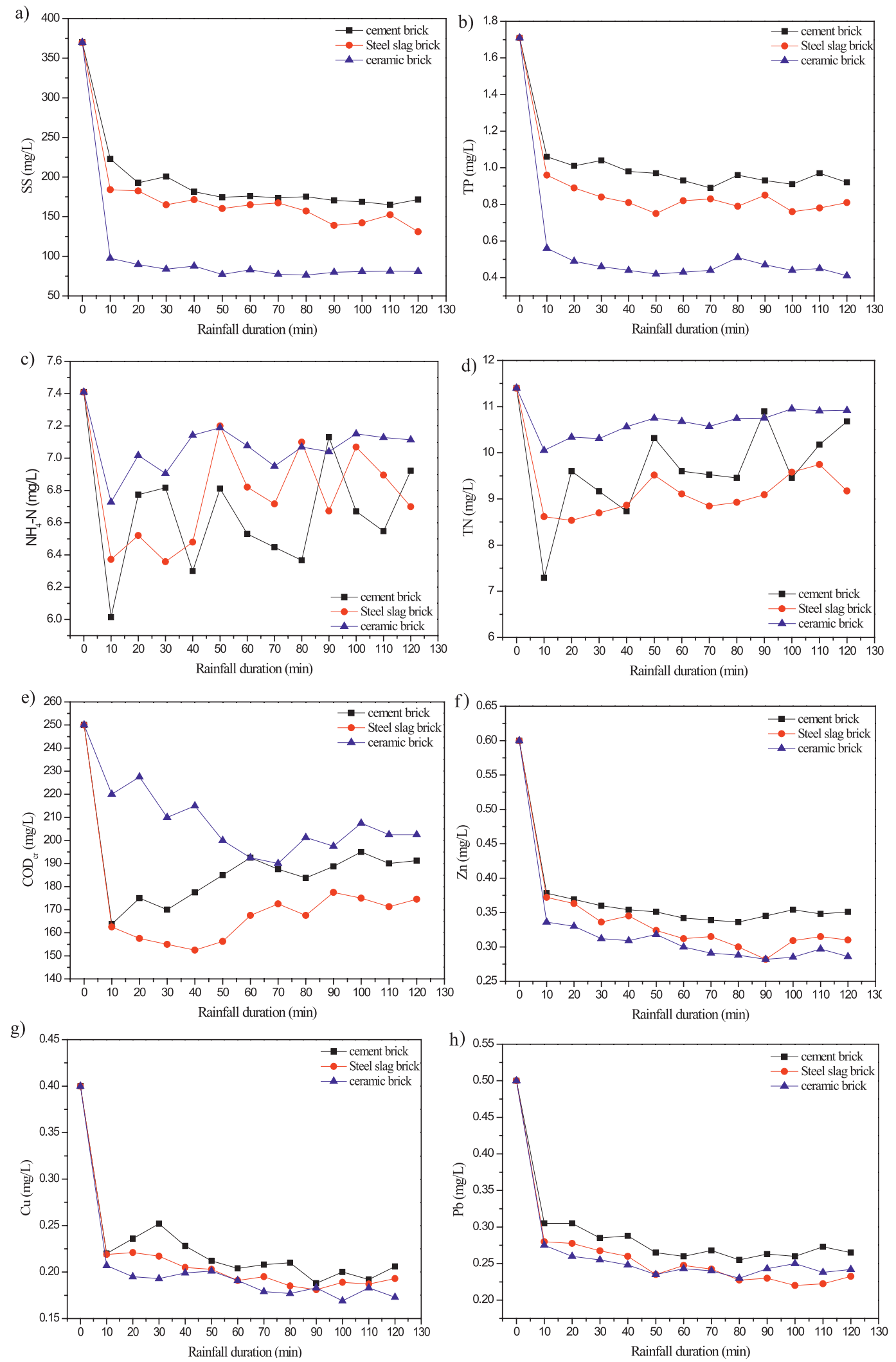

Fig. 4. Filtration removal of pollutants at different times in three types of bricks. 


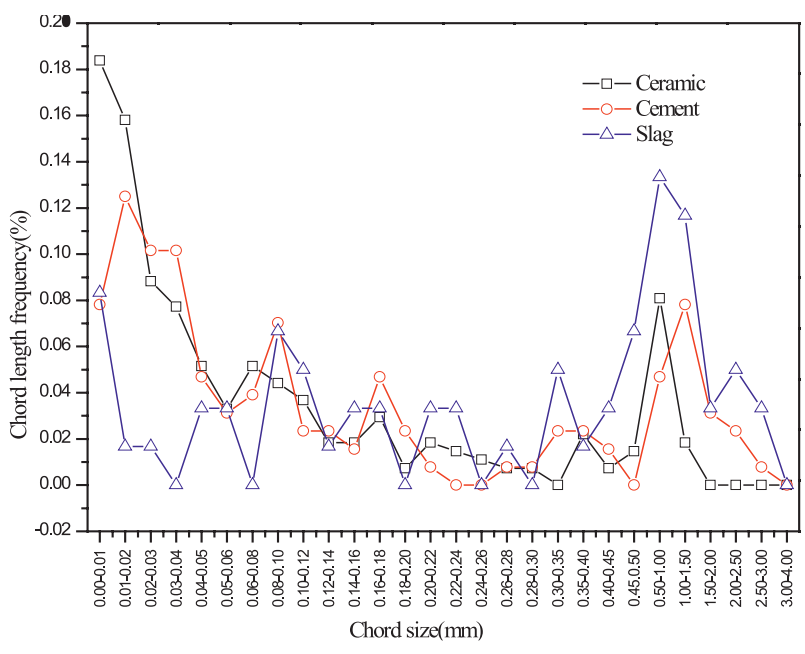

Fig. 5. Chord size distribution of the upper layer of three types of bricks.

effect [29]. In fact, the dense structure of the upper layer lying on the bottom layer favored the physical retention of SS for all of the permeable bricks; obviously, the uniform and dense pore distribution of the ceramic permeable brick was more instrumental in the retention of particulates.

The filtration removal of TP at different times in the three permeable bricks is shown in Fig. 4b). As shown in Fig. 4b), the ceramic permeable brick had the best filtration effect in the filtration experiment, while the cement brick had the worst efficiency, which showed that adsorption was of little significance to the removal of TP compared to filtration. Eck et al. found that TP was easily adsorbed on suspended particles and removed with the SS by the filtration of the permeable brick [30], which was consistent with the conclusions of this research. This is also the reason why the trends in Fig. 4a) and Fig. 4b) were consistent in this study.

The filtration removal of heavy metals at different times in the three permeable bricks is shown in Fig. (f, g, h). The heavy metals were usually removed along with the filtering of the SS by the permeable bricks $[2,14,15,18,31,32]$; therefore, the removal rates of $\mathrm{Zn}, \mathrm{Cu}$ and $\mathrm{Pb}$ were also relatively high. Due to the different binding abilities between the heavy metals and particles in the runoff, the removal rates of $\mathrm{Zn}, \mathrm{Cu}$ and $\mathrm{Pb}$ by several packing systems were inconsistent [33].

The filtration effect of ammonia nitrogen was poor from the actual filtration effect, and there may be two reasons for this poor efficiency. The first is the dissolution and emission of ammonia nitrogen from the brick materials, and the more important reason is the poor adsorption capacity of the particles themselves to ammonia nitrogen. The removal of $\mathrm{NH}_{4}^{+}-\mathrm{N}$ was mainly due to adsorption and ion exchange of the ammonia nitrogen by the permeable brick [2, 15, 18], and the dissolved ammonia ions were difficult for the permeable bricks to filter and retain [18].
The filtration removal of $\mathrm{TN}$ at different times in the three permeable bricks is shown in Fig. 4d). Similar to ammonia nitrogen, the permeable brick materials also had TN dissolution and emission in the adsorption process, and the filtration effect of $\mathrm{TN}$ was not very ideal. In our research, TN was composed of $\mathrm{NH}_{4}^{+}-\mathrm{N}$ and $\mathrm{NO}_{3}^{-}-\mathrm{N}$, and the trend of change in the TN concentration was similar to that of $\mathrm{NH}_{4}^{+}-\mathrm{N}$ because the anion $\mathrm{NO}_{3}{ }^{-} \mathrm{N}$ was also not easily adsorbed or filtered by the three types of bricks [34].

The filtration removal of COD at different times in the three permeable bricks is shown in Fig. 4e). As shown in Fig. 4e), the steel slag permeable brick had the best filtration effect in the filtration experiment, while the ceramic brick had the worst efficiency, which showed that the dissolution of COD had a negative effect on the filtration removal. In the adsorption experiment, the order of COD adsorption efficiency was steel slag brick $>$ cement brick $>$ ceramic permeable brick, and the trend of filtration was consistent with the order of adsorption. Static adsorption experiments showed that there was COD released from the ceramic and cement permeable bricks, which may be the main reason for the poor removal rate of the ceramic and cement bricks among the three bricks. Overall, the COD removal rate of the three permeable bricks was low, and the removal rate was $20-32 \%$.

All three permeable bricks to some extent removed $\mathrm{NH}_{4}^{+}-\mathrm{N}, \mathrm{TN}$ and $\mathrm{COD}$, which indicated that the bricks had good stability in actual use with no serious pollutant released.

\section{Removal of Organic Carbon in Actual Road Rainwater by Permeable Bricks}

To fully investigate the removal effect of permeable brick on actual road rainwater, the TOC and DOC of road rainwater were measured in the dynamic filtration experiment. The actual removal of organic carbon in road rainwater by the three bricks is shown in Fig. 6 .

As shown in Fig. 6, in the actual road rainwater, most of the organic carbon was insoluble [35, 36],

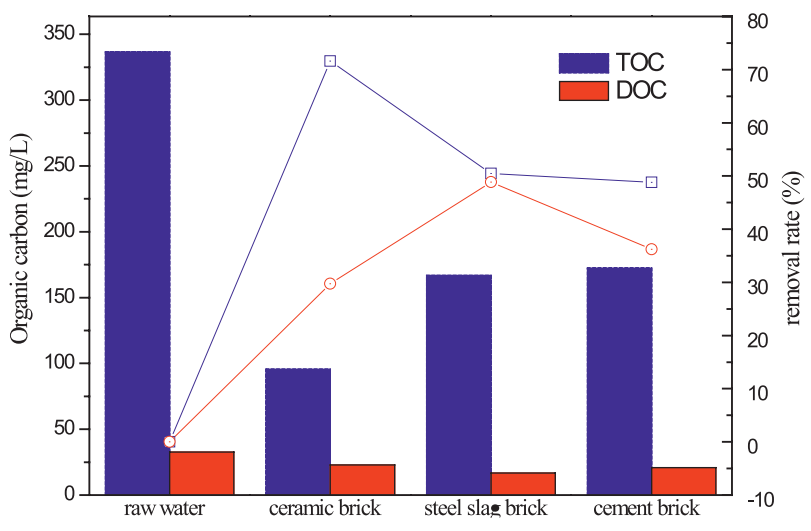

Fig. 6. Actual removal of organic carbon in road rainwater by three types of bricks. 
and the soluble organic carbon accounted for approximately $10 \%$ of the total content. The ceramic permeable brick had a larger TOC removal efficiency, indicating that the compact and dense pore distribution structure was conducive to the removal of insoluble organic carbon by physical interception, especially for organic carbon with particles larger than $0.45 \mu \mathrm{m}$, which was the difference between TOC and DOC. Contrary to the removal efficiency of TOC, non-sintered brick such as the steel slag brick and cement brick had higher DOC removal efficiency, which meant higher removal efficiency for organic carbon with particles smaller than $0.45 \mu \mathrm{m}$, which may be due to the flocculation of cement hydration products.

\section{Conclusions}

In this study, ceramic permeable brick, cement permeable brick, and steel slag permeable brick were selected to study decontamination performance. An adsorption experiment with particle materials obtained by crushing the bricks and a filtration experiment with complete bricks were carried out to explore the removal mechanism of pollutants. Based on the results from this study, the following conclusions could be drawn.

(1) The concentrations of $\mathrm{NH}_{4}^{+}-\mathrm{N}, \mathrm{TN}$ and $\mathrm{COD}$ increased for most particulate materials during the adsorption process. These three components were contained in the brick, and these pollutants in the bricks dissolved into the aqueous solution after breaking and soaking, which may be the reason for their increase in concentration. Nonsintered bricks such as the cement brick and steel slag brick containing a certain amount of cement increased the $\mathrm{pH}$ after adsorption.

(2) The physical interception of the surface layer played a critical role in the SS filtration process, and the uniform and dense pore distribution was instrumental in the retention of particulates. TP was easily adsorbed on the suspended particles, while heavy metals were usually removed along with the filtering of the SS, explaining why the permeable bricks had a relatively high removal rate of these pollutants in the filtration process.

(3) The filtration removal performance of permeable bricks for dissolved pollutants such as $\mathrm{COD}, \mathrm{NH}_{4}^{+}-\mathrm{N}$ and $\mathrm{TN}$ was inferior to that for $\mathrm{SS}, \mathrm{TP}$ and heavy metals. This mainly resulted from two reasons: the difficulty in intercepting the soluble substances and the release of these substances from the brick materials.

(4) The compact and dense pore distribution of the ceramic brick was conducive to the removal of organic carbon with particles larger than $0.45 \mu \mathrm{m}$ by physical interception, and the non-sintered bricks had higher DOC removal efficiency because of the flocculation of cement hydration products, which meant higher removal efficiency for organic carbon with particles smaller than $0.45 \mu \mathrm{m}$.

\section{Acknowledgements}

This study was supported by the National Natural Science Foundation of China (No. 51608272), the Science and Technology Project of Jiangsu Provincial Construction System (No. 2018ZD203), the Science and Technology Project of Nanjing Municipal Construction System (No. Ks1914), and the Student's Innovative Projects of Nanjing Forestry University (2018NFUSPITP769, 2019NFUSPITP0504).

\section{Conflict of Interest}

The authors declare no conflict of interest

\section{References}

1. SOUNTHARARAJAH D.P., LOGANATHAN P., KANDASAMY J., VIGNESWARAN S. Removing heavy metals using permeable pavement system with a titanate nano-fibrous adsorbent column as a post treatment. Chemosphere. 168, 467-473, 2017.

2. LIU J., YAN H.X., ZHANG K., SCHMIDT A.R., TAO T. Laboratory analysis on the surface runoff pollution reduction performance of permeable pavements. Science of the total environment. 691, 1, 2019.

3. CHANDRAPPA A.K., BILIGIRI K.P. Pervious concrete as a sustainable pavement material research findings and future prospects: a state-of-the-art review. Construction and building materials. 111, 262, 2016,

4. RALLA A., SAADEH S. Sustainable Mitigation of Stormwater Runoff through Fully Permeable Pavement. National Center for Sustainable Transportation, University of California, Davis Research Report. 2018.

5. FASSMAN E.A., BLACKBOURN S. Urban runoff mitigation by a permeable pavement system over impermeable soils. Journal of hydrologic engineering. 15 (6), 475, 2015.

6. COLLINS K.A., HUNT W.F., HATHAWAY J.M. Side-byside comparison of nitrogen species removal for four types of permeable pavement and standard asphalt in eastern North Carolina. Journal of hydrologic engineering. 15 (6), $512,2010$.

7. NEWMAN A.P., PUEHMEIER T., SHUTTLEWORTH A., PRATT C.J. Performance of an enhanced pervious pavement system loaded with large volumes of hydrocarbons. Water Science and Technology. 70 (5), 835, 2014.

8. BROWN R.A., BORST M. Evaluation of surface infiltration testing procedures in permeable pavement systems. Journal of Environmental Engeering. 140 (3), 82, 2014.

9. CHU L., FWA T.F. Evaluation of surface infiltration performance of permeable pavements. Journal of Environmental management. 238, 136, 2019.

10. BOOGAARD F., LUCKE T. Long-Term Infiltration Performance Evaluation of Dutch Permeable Pavements Using the Full-Scale Infiltration Method. Water. 11 (2), 320, 2019.

11. LEGRET M., COLANDINI V., MARC C.L. Effects of a porous pavement with reservoir structure on the quality 
of runoff water and soil. Science of the total environment. 189-190, 335, 1996.

12. WEISS P.T., KAYHANIAN M., GULLIVER J.S., KHAZANOVICH L. Permeable pavement in northern North American urban areas: research review and knowledge gaps. International journal of pavement engineering. 20 (2), 143, 2017.

13. OSTROM T.K., DAVIS A.P. Evaluation of an enhanced treatment media and permeable pavement base to remove stormwater nitrogen, phosphorus, and metals under simulated rainfall. Water Research. 166, 115071, 2019.

14. JIANG W., SHA A.M., XIAO J.J., LI Y.L., HUANG Y Experimental study on filtration effect and mechanism of pavement runoff in permeable asphalt pavement. Construction and building materials. 100, 102, 2015.

15. DRAKE J.A., BRADFORD A., MARSALEK J. Review of environmental performance of permeable pavement systems: state of the knowledge. Water Quality Research Journal of Canada. 48, 203, 2013.

16. LI H., LI Z., ZHANG X., LI Z., LIU D., LI T., ZHANG Z. The effect of different surface materials on runoff quality in permeable pavement systems. Environmental Science and Pollution Research. 24 (26), 21103, 2017.

17. ZHANG Z,Y., LI Z.F., ZHANG X.R., LIU D.Q., LI Z.R., LI H.Y. Systematically Investigated the Influences of Permeable Pavement Materials on the Water Quality of Runoff: Batch and Column Experiments. Water Air and Soil Pollution. 229 (5), 155, 2018.

18. NIU Z.G., LV Z.W., ZHANG Y., CUI Z.Z. Stormwater infiltration and surface runoff pollution reduction performance of permeable pavement layers. Environmental Science and Pollution Research. 23 (3), 2576, 2016.

19. HUANG J.L., DU P.F., AO C., HO M., LEI M., ZHAO D., WANG Z. Multivariate analysis for stormwater quality characteristics identification from different urban surface types in Macau. Bulletin Environmental Contamination and Toxicology. 79 (6), 650, 2007.

20. HELMREICH B., HILLIGES R., SCHRIEWER A., HORN H. Runoff pollutants of a highly trafficked urban road - Correlation analysis and seasonal influences. Chemosphere. 80 (9), 991, 2010.

21. GRZMIL B., WROMLOWSKI J. Removal of phosphates and fluorides from industrial wastewater. Desalination. 189 (1-3), 261, 2006.

22. PARK J.Y., BYUN H.J., CHOI W.H., KANG W.H. Cement paste column for simultaneous removal of fluoride, phosphate, and nitrate in acidic wastewater. Chemosphere. 70 (8), 1429, 2008.

23. DIMITRIS D., MENG X.G. Utilization of fly ash $\mathrm{f}$ or stabilization of heavy met al cont aminat ed soils. Engineering Geology. 70 (3-4), 377, 2003.
24. THEVENIN G., PERA J. Interactions between lead and different binders. Cement and Concrete Research. 29 (10), $1605,1999$.

25. YOUSUF M., MOLLAH A. An infrared spectroscopic examination of cement based solidificati on and stabilizati on systems-Portland types V and IP with zinc. Journal of Environmental Science and Health. Part A. 27 (6), 1503, 1992.

26. KOUPAI J.A., NEJAD S.S., MOSTAFAZADEH-FARD S., BEHFARNIA K. Reduction of Urban Storm-Runoff Pollution Using Porous Concrete Containing Iron Slag Adsorbent. Journal of Environmental Engineering-Asce. 142, 04015072, 2016.

27. LIU C.F., SHIH S.M. Iron blast furnace slag/hydrated lime sorbents for flue gas desulfurization. Environmental Science and Technology. 38 (16), 4451, 2004.

28. YONG C.F., MCCARTHY D.T., DELETIC A. Predicting physical clogging of porous and permeable pavements. Journal of Hydrology. 481, 48, 2013.

29. WINSTON R.J., AL-RUBAEI A.M., BLECKEN G.T., VIKLANDER M., HUNT W.F. Maintenance measures for preservation and recovery of permeable pavement surface infiltration rate-the effects of street sweeping, vacuum cleaning, high pressure washing, and milling. Journal of Environmental Management. 169 (2), 132, 2016.

30. ECK B.J., WINSTON R.J., HUNT W.F., BARRETT M.E. Water Quality of Drainage from Permeable Friction Course. Journal of Environmental Engineering. 138 (2), 174, 2015.

31. RAZZAGHMANESH M., BORST M. Long-term effects of three types of permeable pavements on nutrient infiltrate concentrations. Science of the total environment. 670, 893, 2019

32. BALL J.E., JENKS R., AUBOURG D. An assessment of the availability of pollutant constituents on road surfaces. Science of the total environment. 209 (2-3), 243, 1998.

33. STAGGE, J.H., DAVIS, A.P., JAMIL, E., KIM, H. Performance of grass swales for improving water quality from highway runoff. Water Research. 46(20), 6731, 2012

34. LI L., DAVIS A.P. Urban Stormwater runoff nitrogen composition and fate in bioretention systems. Environmental Science and Technology. 48 (6), 3403, 2014.

35. DING Q.L., WANG Q., ZHANG Q.H., WANG X.C., MAWULI D. Analysis of runoff pollution from the main road in Yixing City, Taihu Lake Basin. Acta Scientiae Circumstantiae. 37 (9), 3456, 2017 [In Chinese].

36. ZHANG J.J., JIANG Y.Z., LIU A., GUAN Y.T., YE S.H. Characterizing urban road runoff quality in south China: a case study in Shenzhen. Journal of Southeast University. 30 (2), 181, 2014. 
